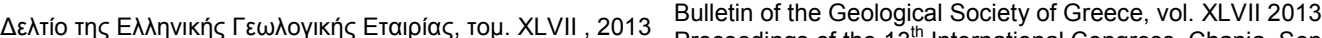

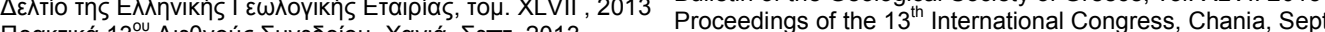

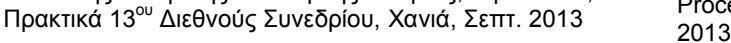

\title{
GEOPHYSICAL INVESTIGATION AND ITS GEOLOGICAL INTERPRETATION IN THE FRAME OF AN INTERGRATED SURVEY PRIOR TO A DAM CONSTRUCTION IN PLATI RIVER VALLEY, RETHYMNO, GREECE
}

\author{
Apostolopoulos G. ${ }^{1}$, Pavlaki C. ${ }^{2}$, Perleros V. ${ }^{3}$ and Amolochitis G. ${ }^{4}$ \\ ${ }^{l}$ School of Mining and Metallurgical Engineering, Applied Geophysics Laboratory, National \\ Technical University of Athens, 9 Iroon Polytechniou Str., 15780 Zografou, Greece, \\ gapo@metal.ntua.gr \\ ${ }^{2}$ Consultant for Geological Surveys, 56 Tzanakaki Str., 73134 Chania, Greece,catrpaul@otenet.gr \\ ${ }^{3}$ Consultant for Geological Surveys, 56 Dionysou Str., 15234 Chalandri, \\ Greece,perlerosv@gmail.com
}

${ }^{4}$ School of Mining and Metallurgical Engineering, Applied Geophysics Laboratory, National Technical University of Athens, 9 Iroon Polytechniou Str., 15780 Zografou, Greece,

amoloh@metal.ntua.gr

\begin{abstract}
A geophysical survey using electrical resistivity tomography (ERT) method(25 ERT profiles of $240 \mathrm{~m}$ total length and 2 ERT profiles of $1000 \mathrm{~m}$ total length) in the area of Plati River valley gave valuable information regarding the stratigraphy, related to loose sediments, various faces of flysch and limestone, the tectonic status and the detection of areas of thick and extensive sheared siltstone, that geoelectrically is similar to clay, material useful for the core of the future dam. Both branches of river and valley and in greater detail the area near the position of the dam have detected showing the underground in a 2D and 3D manner. The thickness of neogene and flysch exceeds $40 \mathrm{~m}$. Alternations of siltstones-sandstones are met in flysch and in places cohesive sandstones are also met without continuation in an extended area. The siltstonelayers due to their shear character present clayey characteristics in respect of their resistivities. In general zones of limestone uplift have not been detected, which may create problems of leakages apart of the dam area where lateral inhomogeneity between flysch and limestone has been detected (probable fault). The various limestone bodies met in flysch or neogene do not have continuation in depth and they are isolated.
\end{abstract}

Key words:Resistivity, Tomography, Schlumberger Array, Pole-Dipole Array.

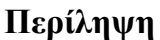

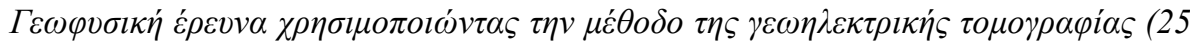

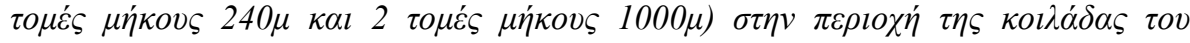

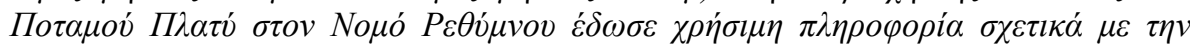

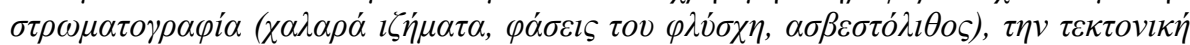

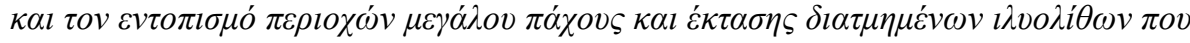

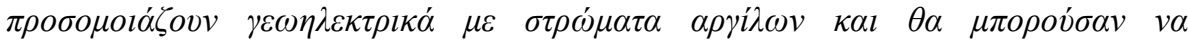




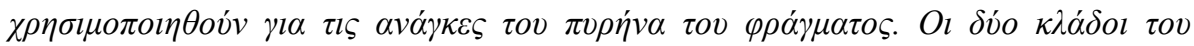

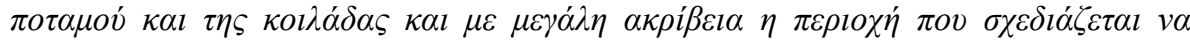

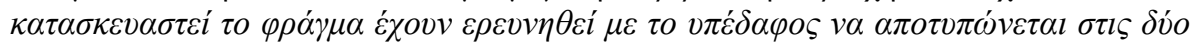

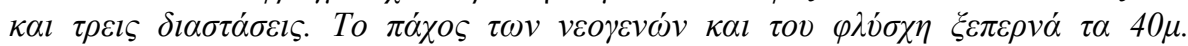

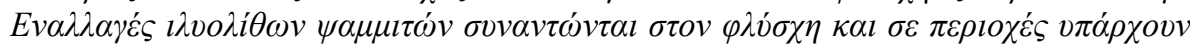

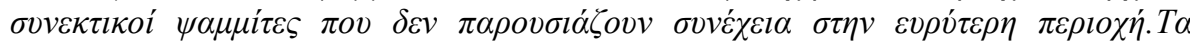

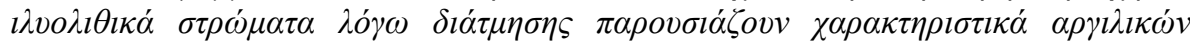

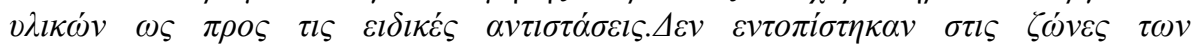

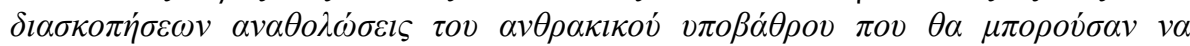

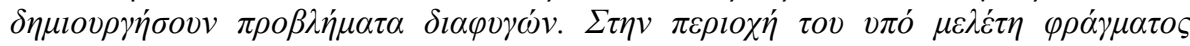

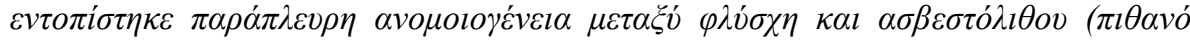

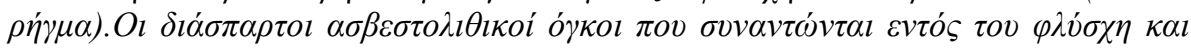

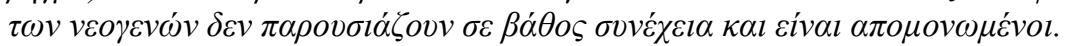

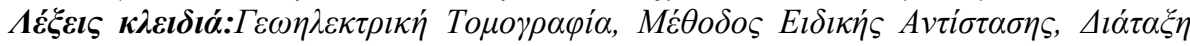

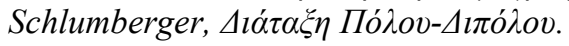

\title{
1. Introduction
}

The quality of an integrated geological-geotechnical survey is one of the critical aspects for the "health" and durability of big construction projects as they are the dam and artificial lake construction. A useful tool for the better understanding of the subsurface along with the necessary drillings is the appropriate geophysical investigation. Appropriate since the expected geological formations will judge which geophysical methods can distinguish interfaces, local features, possible tectonic structure. The use of geophysical investigation proved important prior or after dam construction in Greece,Louis et al. (1992), Apostolopoulos et al. (1999), Karastathis et al. (2002) or elsewhere Sjödahl et al. (2006), Hunterand Powers (2008).

Main objectives of a geophysical survey in these applications are the detection of the stratigraphy, the tectonic status and the detection of places for large amounts of fine grain clay material useful for the dam construction. The design of this geophysical survey is such to see these objectives a) with scattered profiles in the whole valley covered by water and nearby region in order to predict phenomena after water coverage and $b$ ) with dense coverage of profiles in the area of the dam to give information to construction issues and possible leakage phenomena.

Finally the design of the geophysical survey is the result of the collaboration between geologists and geophysicists who consider all aspects both the demands of the project and qualitative geophysical data. Some displacements occur during the field work due to local obstacles (fences, human activities, etc.)

\section{Geology of the Area}

The geological structure of the Platy River region bears characteristics of compressional tectonics with old over-thrusting structures related to plate convergence followed by extensional tectonics with the development of normal faults developed during the southern migration of the subduction zone.

The study area comprises of geological formations of the Pindos and Arvis geotectonic units that correspond to the upper tectonic nappes of Crete. These formations include (Figure 1):

- Flysch transition beds of siltstone, calcareous sandstone and clay and the upper Pindos Flysch. The upper Pindos Flysch predominates in the foundation zone and catchment basin of the Platis dam and is composed mainly of sandstone and siltstone intercalations and occasional clay and low grade metamorphic formations. In the dam zone, intense tectonic deformation has resulted in fractured sandstone formations and faulted siltstone formations.

$\underline{\text { XLVII, No } 3-1053}$ 
- Transition beds composed of intercalations of thin-bedded limestone, sandstones, siltstones and chert.

- Local outcrops of thin-bedded platy Pindos limestone with chert intercalations that develop below the dam zone, and outcrops in the form of an exhumed overthrust ridge that dip at high angles to the North along a normal fault trace. The thin-bedded limestones also outcrop in the catchment basin along the Lygiotis stream gorge.

- Local outcrops of unstratified residual limestone, thrusted over the flysch in the form of minor tectonic nappes, boulders or relics that developed during the overthrust process. Due to the variable mechanical properties of limestone they were separated and thrusted independently over the flysch. Limestone boulders of various dimensions were recorded on the left buttress overlying the elluvial layer of flysch, scattered in various locations in the catchment basin and its limits. These outcrops were studied by geophysical exploration.

- Neogene and Quaternary sediments, comprising conglomerates, marls, sandstones, clays, silts and sands.

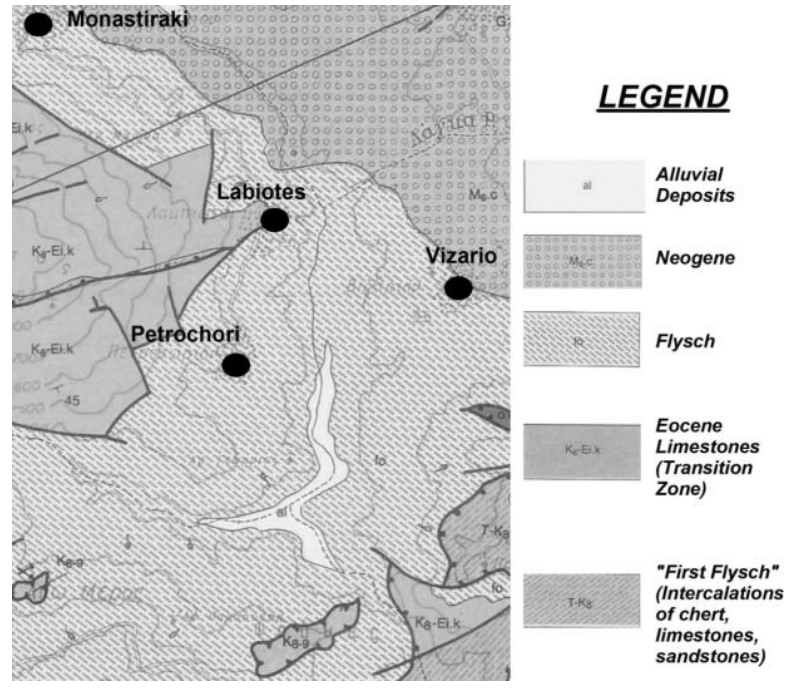

Figure 1 -Geological map of the survey area (part of IGME geol. map "Melambes", 1985).

\section{Geophysical Survey}

The best geophysical method in order to distinguish formations of different grain size in loose sediments, the various phases of flysch and interfaces with limestone is the resistivity method and in particular the Electrical Resistivity Tomography (ERT) technique to detect in great detail both stratigraphy and local features.

The geological formations of the area have different resistivities. Clay has $10-500 \mathrm{hm} . \mathrm{m}$ (depending on the grain size, the moisture, the compaction), pebbles $200-500 \mathrm{Ohm}$.m, flysch 80 $170 \mathrm{Ohm} . \mathrm{m}$ (depending on its phase), limestone $500-3000 \mathrm{Ohm} . \mathrm{m}$. In greater detail coloring and classification of various resistivities shown in resistivity sections is shown in Figure 2

Twenty-five (25) ERT profiles of $240 \mathrm{~m}$ total length and $5 \mathrm{~m}$ electrode spacing are scattered in the two branches of the valley and densely positioned in the area of the dam (labeled with $\mathrm{R}^{*}$ in Figure 2). These profiles will give the stratigraphy and local features in great detail. Two (2) ERT profiles of $1000 \mathrm{~m}$ total length and $50 \mathrm{~m}$ electrode spacing are positioned along the big $(\mathrm{N}-\mathrm{S})$ branch of the valley to detect deeper geological formations (labeled R100* in Figure 2).Schlumbereger electrode configuration was selected since accuracy in stratigraphy is the main target of the survey. One (1) ERT profile (Figure 2, "RPD") at the position of the dam with $355 \mathrm{~m}$ 
total length and $5 \mathrm{~m}$ electrode spacing used Pole-Dipoleelectrode configuration in order to detect both lateral and horizontal discontinuities in great detail.

Accurate positioning and leveling of the profiles and their electrodes was made with Differential LeicaGPS1200. Resistivity measurements were acquired with two instruments ABEM SAS1000 and IRIS SYSCAL-PRO-72.

Analysis of the results as shown with resistivity sections of some indicative profiles (Figures 3,4) as we go from north and west to the position of the dam in the south is following.

ERT section "R-23" (Figure 3) shows a fine grain clayey-sandy material of very low resistivities on the top overlying clay material (dashed line shows their interface) while to the south-east there is a body of sandstone. These are characteristically Neogene formations.

ERT section "R-18" (Figure 3) shows on its northwest part a highly resistive surface layer of coarse material (pebbles) which overlays on clay with some coarse material (intermediate resistivities) and all of them on clay that extends in the whole section. ERT section "R-16", been on the opposite west side of the valley in respect of "R-18", south of Petrochori village, shows a surface layer of intermediate resistivities consisting clay and gravels that overlays on a layer of a fine grained clayey-sandy material and this one overlays to clay. In the north-west part of this last clayey layer there is a body of higher resistivities possibly sandstone.

In the left branch of the valley both sections "R-2" and "R-4" (Figure 3) show a surface layer of high resistivities with pebbles which overlays a layer of fine grain clay material (clayey phase of flysch, low resistivities) and that overlays a "sandstone phase of flysch" (intermediate resistivities) and in "R-4" been underneath of it as well.

In the area of the future dam construction both ERT sections "R-6" and "R-7" (Figure 4) show a surface layer of high resistivities with pebbles which overlays flysch. In the layer of flysch there is a medium of higher resistivities which can be cohesive sandstone and where there are intermediate resistivities a loose sandstone phase of flyschmay exist. The lower resistivities correspond to the clayey phase of flysch. The ERT section "RPD" (Figure 4) with the pole-dipole electrode configuration with greater depth detection and sensitive to lateral inhomegeneities, shows the highly resistive surface layer of pebbles followed deeper by low resistivity clay layer. Deeper there is the highly resistive limestone whose top is outlined by a small dashed line. At distance of $-250 \mathrm{~m}$ there is a deep lateral interface separating flysch and limestone probably showing a fault. Surface manifestations indicate that as well.

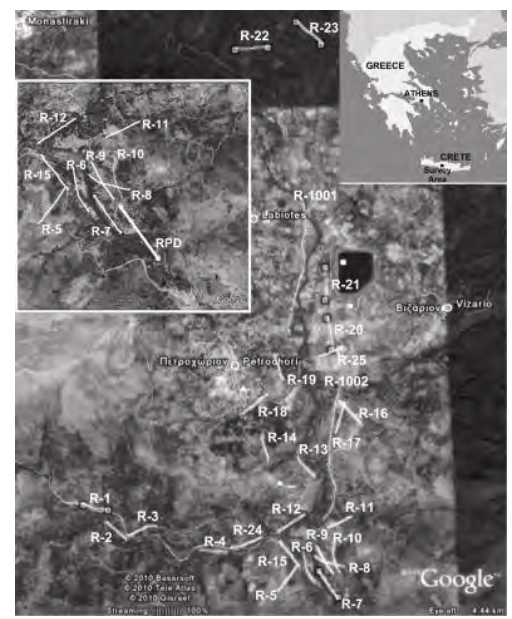

Figure 2 - ERT profiles on a Google map scattered in the two branches of Platis River valley near Petrochori village. In the small picture with greater detail more dense coverage of profiles in the area of future dam.

XLVII, No 3 - 1055 

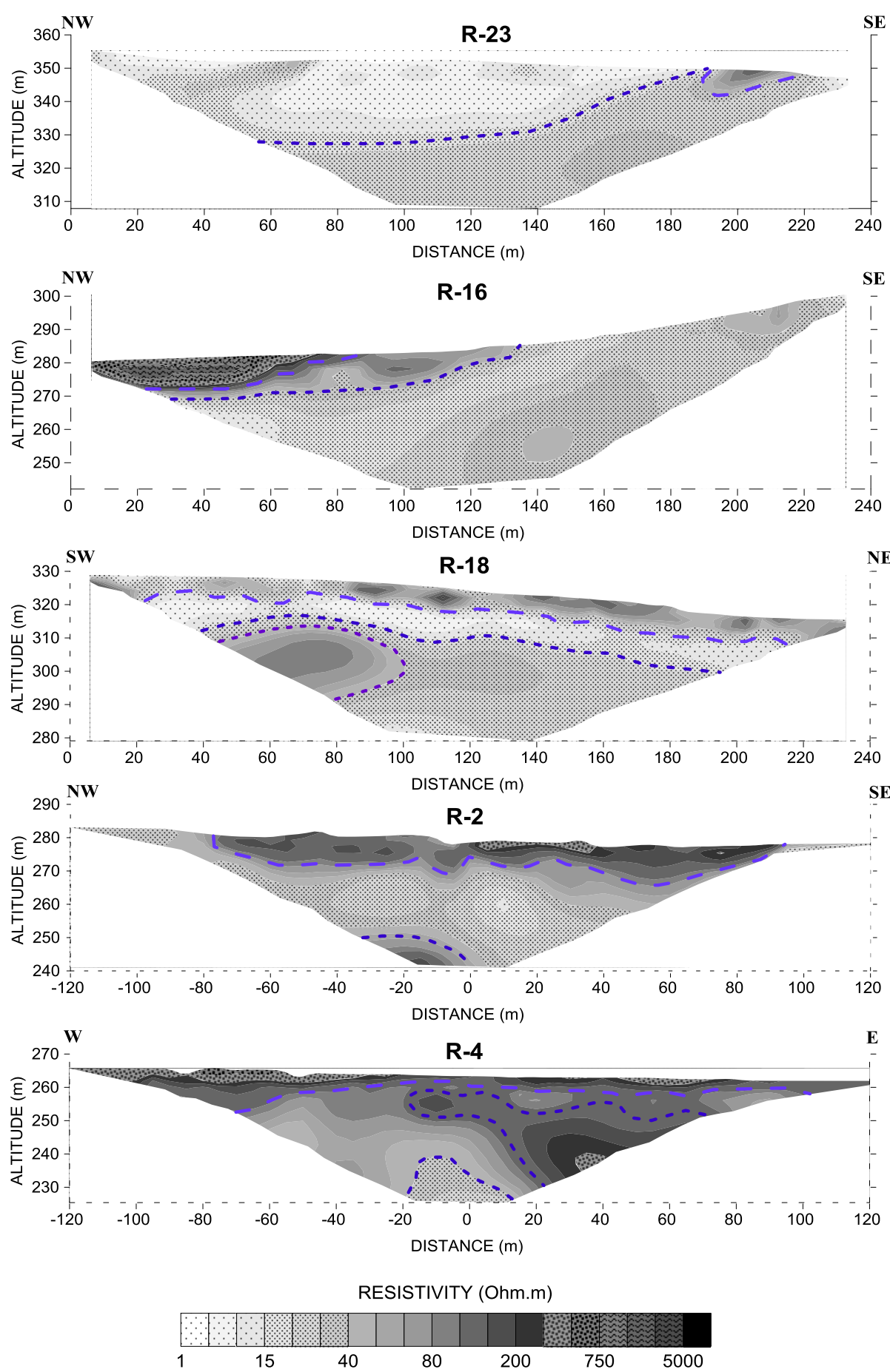

Figure 3 -ERT sections "R-23", "R-16", "R-18", "R-2" and "R-4". Resistivity distribution with depth is shown along with the main interfaces between main formations with dashed lines.

$\underline{\text { XLVII, No } 3-1056}$ 

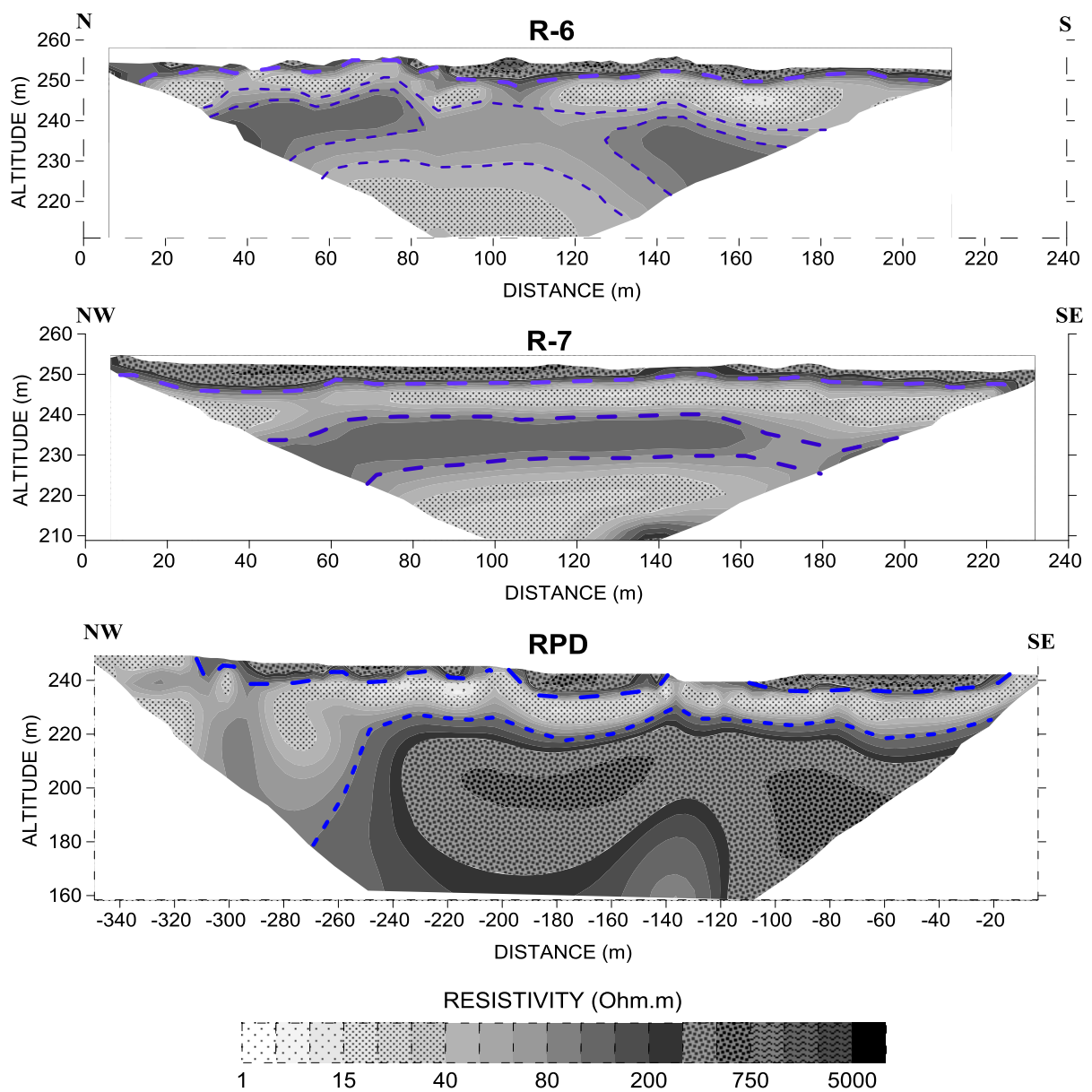

Figure 4 -ERT sections "R-6", "R-7" and "RPD". Resistivity distribution with depth is shown along with the main interfaces between main formations with dashed lines.

Long ERT sections of $800 \mathrm{~m}$ length and greater depth of detection $(80-100 \mathrm{~m})$, "R-1001" and "R1002" (Figure 5) made to see the general stratigraphy along the north-south branch of the valley. These two ERT long sections show that from the north part of the survey area to the region where the two branches of the river meet together there is a surface layer of coarse material and deeper fine grain clayey materials exist. These clayey materials show different resistivities (the presence of sand increases the resistivity value) and the very low resistivities of the deep layer in section "R-1001" represent Neogene formations while in its southern part as well as in the whole section "R1002" the deeper low to intermediate resistivities represent flysch formations.

All resistivity sections southwards from R-20 and eastwards from R-4, can lead to the following results:

- From the north part of the survey to the area where the two branches of the river meet together there is a surface layer of coarse material and deeper fine grain clayey materials exist.

- In the area of left west branch of the river and in the area of the dam construction the surface layer of coarse material overlays flysch of various phases, high resistive corresponding to the cohesive sandstone, intermediately resistive to the loose sandstone phase and conductive to the clayey phase. 
- At the dam construction site, where "RPD" ERT profile is, there is a lateral interface between flysch and limestone probably related to a fault.
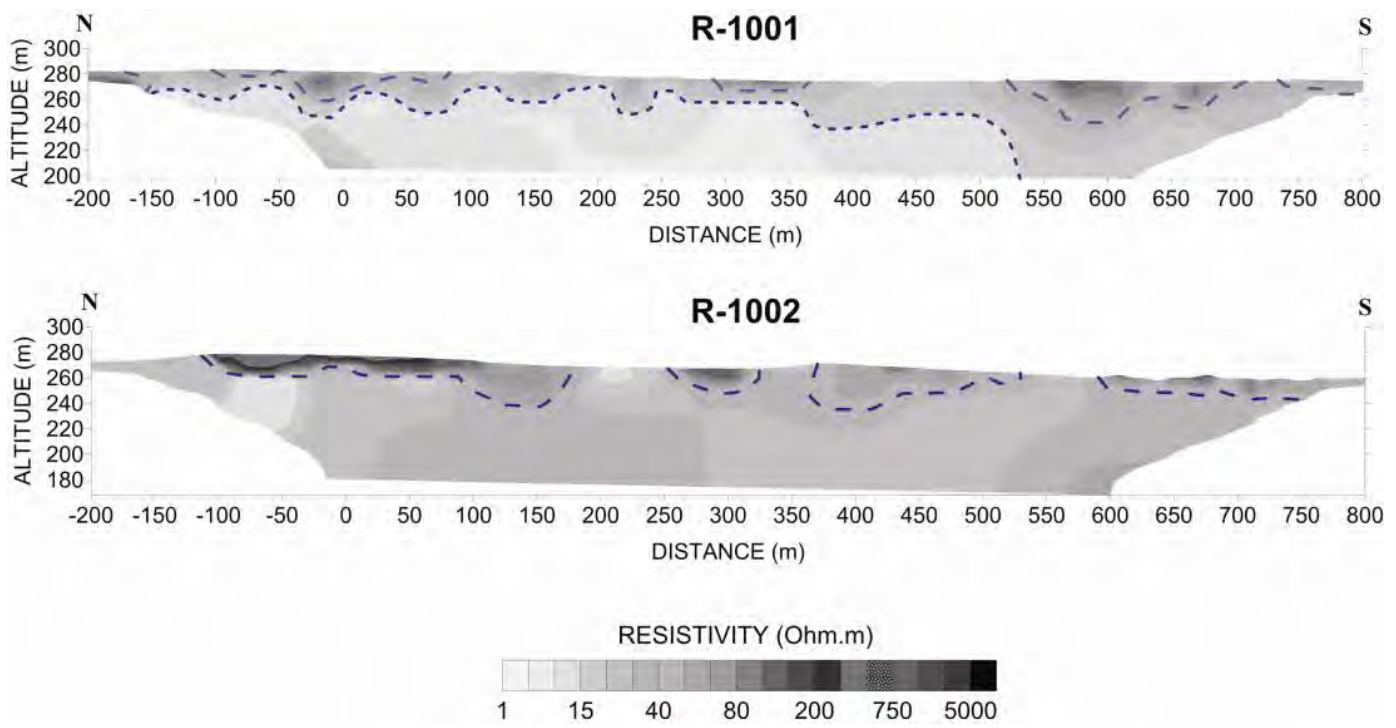

Figure 5 -Long ERT sections (800m length) with great depth of detection along the northsouth branch of the valley. Resistivity distribution with depth is shown along with the main interfaces between main formations with dashed lines.

The previous observations can be seen in Figure 6 where horizontal distribution of resistivity is presented in various levels - altitudes. We see the low resistivities dominating the northern part (altitudes: $320 \mathrm{~m}-290 \mathrm{~m}$ ) with fine grained clayey material, an accumulation of high resistivities at altitude $300 \mathrm{~m}$ related to coarse material (gravels, river activity), the presence of flysch with higher resistivities in the south part at altitude $290 \mathrm{~m}$, the presence of cohesive sandstone phase at altitudes $280 \mathrm{~m}-270 \mathrm{~m}$ and deeper the clayey phase of flysch be dominant.

\section{Conclusions}

The objective of the geophysical survey was to detect the underground in the zone of the dam foundation and in the catchment area in respect of layer thickness of flysch and neogene and the probable uplift of the bedrock (limestone). It was also detected the continuation in depth of various limestone bodies which are in Flysch or above neogene.

The design and parameters of the geophysical survey by the application of electrical resistivity tomography have followed the demands of the project as well rules for their best quality.

The geophysical survey has shown that in the whole catchment area the thickness of neogene and flysch exceeds $40 \mathrm{~m}$. Alternations of siltstones-sandstones are met in flysch and in places cohesive sandstones are also met without continuation in an extended area. The mudstone layers due to their shear character present clayey characteristics in respect of their resistivities. In general zones of limestone uplift have not been detected, which may create problems of leakages apart of the dam area where lateral inhomogeneity between flysch and limestone has been detected (probable fault). The various limestone bodies met in flysch or neogene do not have continuation in depth and they are isolated.

Boreholes after the geophysical survey were positioned in the best manner to interpret in geological-geotechnical aspect the conclusions of the geophysical results.

The two subsequent borehole projects confirmed the geophysical results (Pavlaki and Perleros, 2012).

$\underline{\text { XLVII, No } 3-1058}$ 


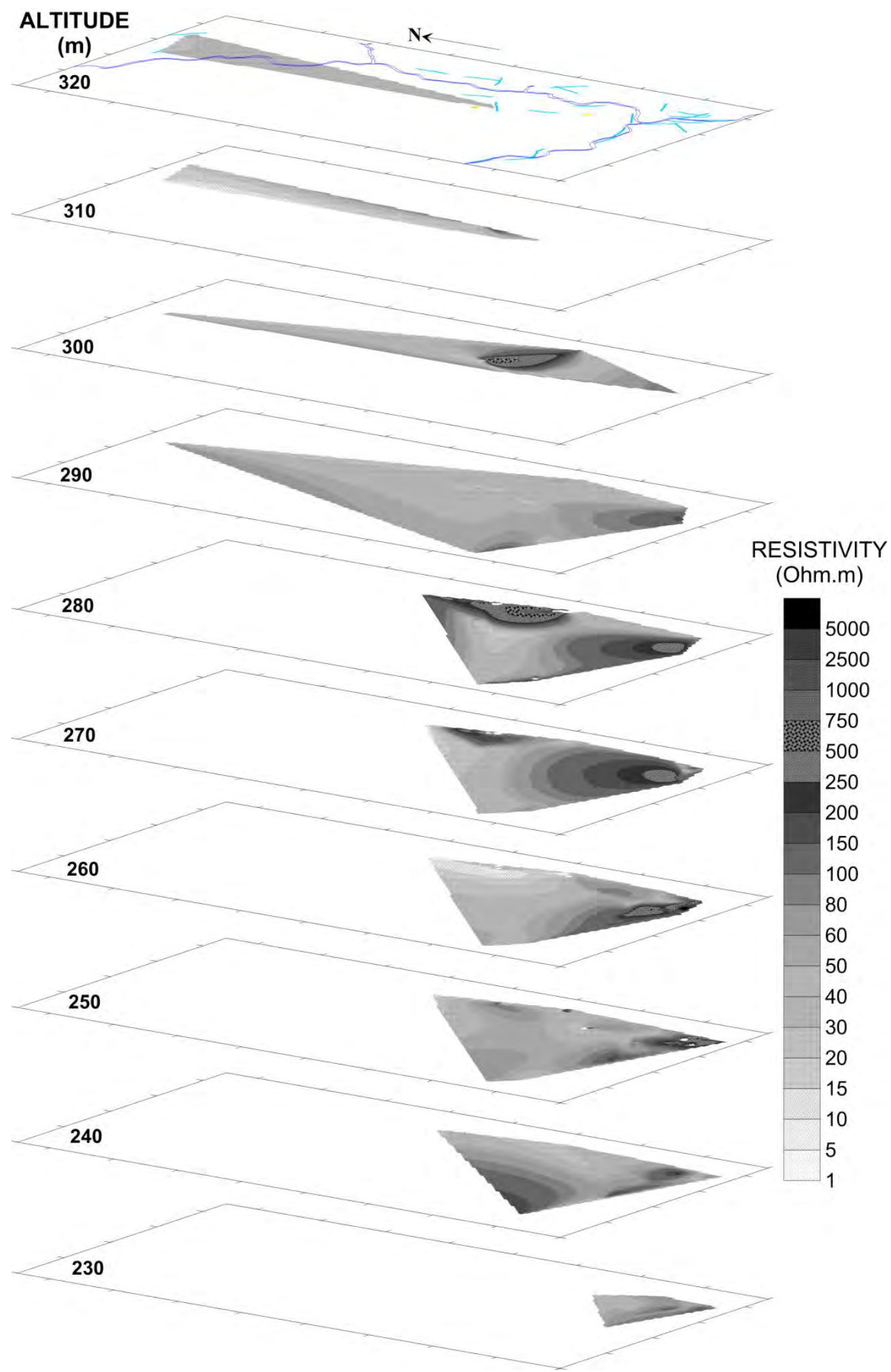

Figure 6 -Horizontal resistivity distribution in various altitudes in the survey area.

$\underline{\text { XLVII, No } 3-1059}$ 


\section{Acknowledgments}

The authors wish to thank for their valuable help during the data acquisition as well as processing the mining engineers - geophysicists Dr. C. Orfanos, Dr. K.Leontarakis, C.Polychronopoulou (M.Sc.) and Dr. G.Fragogiannis.

\section{References}

Apostolopoulos G., Antoniades K. and Pavlopoulos K. 1999. The electrical resistivity method - a useful tool in evaluating geological and geotechnical conditions for construction and engineering projects, Proceedings of $2^{\text {nd }}$ Conference of the Balkan Geophysical Society (BGS), Istanbul, Turkey.

Hunter L. and Powers M. 2008. Geophysical Investigations of Earthen Dams. An Overview, Symposium on the Application of Geophysics to Engineering and Environmental Problems, 1083-1096.

Karastathis V.K., Karmis P.N., Drakatos G. and Stavrakakis G. 2002. Geophysical methods contributing to the testing of concrete dams. Application at the Marathon Dam, Journal of Applied Geophysics 50, 247-260.

Louis J.J., Papadopoulos T., Pantzartzis P. and Apostolopoulos G. 1992. Geophysical engineering conditions at Ilarion damsite, Annales Geologiques des Pays Helleniques 35, 147-163.

Pavlaki C. and Perleros V. 2012. Reconnaissance and final geological study of the area zone of Platy dam. Preliminary and final study of Platy dam in Rethymno County and final study of water pipe to Messara.HMRDF Report.

Sjödahl P., Dahlin T. and Zhou B. 2006. 2.5D resistivity modeling of embankment dams to assessinfluence from geometry and material properties, Geophysics71, no. 3, G107-G114. 